||||||||||||||||||||||||||||||||||||||||||||||||||||||||||||||||||||.

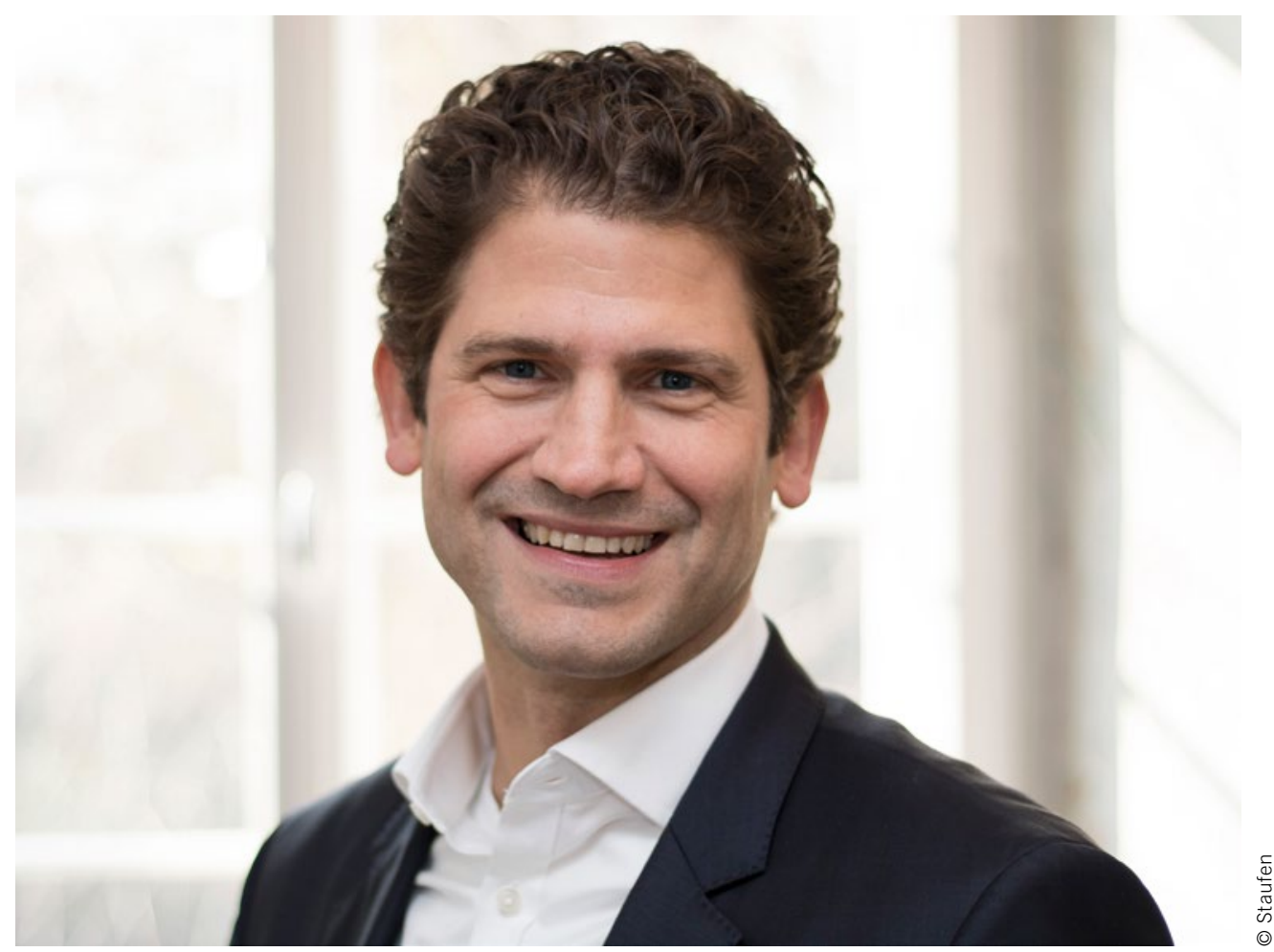

Dr.-Ing. Thilo Greshake

Leiter des Bereichs Automotive bei der Staufen AG

\title{
Die grüne Transformation der Lieferkette
}

Nachhaltigkeit, Ökologie und Klimaschutz wirken im Moment wie Themen von gestern, die weltweite Covid-19-Pandemie bestimmt den Alltag. Trotzdem haben Umweltfragen noch dieselbe Bedeutung wie vor einem Jahr: Die gesamte Automobilindustrie muss ihre grüne Transformation beschleunigen, um nicht von der Wirklichkeit überrollt zu werden.

So diskutiert die deutsche Politik seit einiger Zeit das Lieferkettengesetz. Es soll die Wirtschaft verpflichten, im Ausland beschaffte Vorleistungen oder Vorprodukte unter anderem auch auf umweltschädigende Produktionsbedingungen zu prüfen. Wie auch immer das Gesetz im Detail aussehen wird: Unternehmen benötigen künftig Klarheit, ob in ihrer Lieferkette (Supply Chain) ausreichend auf Nachhaltigkeit geachtet wird. Diese Klarheit bedingt, dass die ökologische Nachhaltigkeit zu einem wichtigen Vergabekriterium wird.

Zumindest in der Automobilindustrie ist das Thema angekommen und wird als zentrale Herausforderung für die nächsten Jahre betrachtet. Laut der Staufen-Studie „Green Transformation in der Automobilindustrie“ sieht sich eine deutliche Mehrheit der Fahrzeughersteller und -zulieferer als Vorreiter bei der Green Transformation. Vor allem die OEMs zeigen sich offen gegenüber ökologischen Aspekten. So haben sie bereits zu mehr als 60 \% die Nachhaltigkeit als Vergabekriterium bei der Lieferantenauswahl festgelegt. Etwas weni- ger aktiv sind die Zulieferer bei wiederum ihren eigenen Lieferanten: Nur knapp 40 \% achten hier schon auf ökologische Themen. So wird deutlich: Das Potenzial für ökologisch nachhaltiges Wirtschaften in der Automotivebranche ist bei Weitem noch nicht ausgeschöpft. Größtes Hemmnis ist die oft fehlende wirtschaftliche Rentabilität vieler ökologischer Maßnahmen. Deshalb konzentrieren sich die Firmen bisher auf Energie- und Materialeinsparung. Das sind klassische Kostensenker, die in der Konsequenz allerdings auch Umweltaspekte positiv berühren.

Entscheidend für die OEMs ist der Einfluss der Verbraucher, die zunehmend ökologische Aspekte berücksichtigen. Bei weiter vom Endkunden entfernten Unternehmen in der Lieferkette hat Nachhaltigkeit dagegen eine geringere beziehungsweise indirekte Bedeutung; hier wirkt also eher das Bestellverhalten der OEMs.

In Zukunft müssen auch die Zulieferer ihre Produktionsanlagen und -prozesse in Richtung Nachhaltigkeit optimieren. Denn die angestrebten $\mathrm{CO}_{2}$-Ziele lassen sich nur innerhalb kompletter Lieferketten erreichen. Ein Weg hierzu ist die Betonung der Umweltaspekte in den Lieferverträgen. Ging es bisher in erster Linie um Qualität und Preis, wird nun auch Ökologie zum zentralen Thema in der Supply Chain der Automobilindustrie. 